\title{
Effects and safety of intravenous injection of formalin on coagulation parameters in healthy dairy cows
}

\author{
Zuhair Bani Ismail*, M. Alekish, M. Awawdeh, and I. Olymat
}

Faculty of Veterinary Medicine, Jordan University of Science and Technology, P.O. Box 3030, Irbid 22110 - Jordan

\author{
Article history \\ Received: 16 Aug, 2016 \\ Revised: 30 Aug, 2016 \\ Accepted: 1 Sep, 2016
}

\begin{abstract}
This study was designed to evaluate the clinico-pathological and toxic effects associated with the intravenous administration formalin solution using 2 different concentrations $(0.37 \%$ and $0.185 \%)$. Six, healthy adult female Holstein cows were used in the study. Whole blood samples were collected before (T0) and again at 15, 30, 60, and 120 minutes and at 24 hours after administration and placed in plain tubes and in EDTA and citrate containing tubes for the evaluation various hematology, serum biochemistry and some coagulation parameters including the activated partial thromboplastin time (APTT), prothrombin time (PT), thrombin time (TT), platelets count, fibrinogen concentrations, and D-dimers. All cows tolerated well the administration of $0.37 \%$ and $0.185 \%$ formalin intravenously. There were no abnormal changes in the hematology and serum biochemistry profiles. In the coagulation profile, the administration of $0.37 \%$ formalin resulted in a significant decrease in APTT clotting times at 30,60, and 120 minutes after administration. Thrombin time was also significantly decreased in this group at 15, 30, 60, and 120 minutes after administration. Platelet count was significantly increased at 60 and 120 minutes in this group. No significant changes were observed in PT values, fibrinogen concentrations and D-dimers at any time point. In cows administered $0.185 \%$ formalin, there was a significant decrease of APTT clotting times at 120 minute that remained at significantly lower levels at 24 hour after administration. Thrombin time was also significantly lower at 15, 30, and 60 minutes after administration. There was no significant difference in PT values, platelet counts, fibrinogen concentrations and D-dimers in this group at any time point. The results of this study showed that the intravenous administration of $0.37 \%$ formalin solution is safe with a pro coagulation effects in normal adult dairy cows. However, further clinical trials in actively bleeding animals are warranted before we safely recommend this treatment in the field.

Keywords: Coagulation profiles; dairy cow; uncontrollable hemorrhage; formalin
\end{abstract}

To cite this article: Ismail ZB, M Alekish, M Awawdeh and I Olymat, 2016. Effects and safety of intravenous injection of formalin on coagulation parameters in healthy dairy cows. Res. Opin. Anim. Vet. Sci., 6(7): 206-210.

\section{Introduction}

Formalin has been widely used in laboratories as a preservative, tissue fixative, disinfectant and an embalming agent for many years. Topical formalin installation has been used to treat both intractable and life-threatening haemorrhages in humans and animals (Jones, 1998; Santschi 1999; Choong et al., 2000;

*Corresponding author: Zuhair Bani Ismail, Department of Veterinary Clinical Sciences, Faculty of Veterinary Medicine, Jordan University of Science and Technology, P.O. Box 3030, Irbid 22110, Jordan; E-mail: zuhair72@just.edu.jo 
Taylor et al., 2000; Doyle et al., 2003; Frazer, 2003; Kang et al., 2003; Henrikson et al., 2004; Lee et al., 2007; Dougherty and Palmer, 2008; Manikandan et al., 2010; Neto et al., 2011; Mohamed et al., 2012). However, there is little scientific evidence exists that supports its efficacy or safety as a pro-coagulant.

Internal and external haemorrhage of various causes is not uncommon and could result in death in cattle (Radostits et al., 2007). Cows with severe haemorrhage are usually treated using blood transfusion, injection of calcium solutions and parenteral coagulants such as adrenochromemonosemicarbazone, or tranexamic acid (Radostits et al., 2007; Divers and Peek, 2008). The use of formalin in bleeding cattle has not been documented before and therefore, this study was carried out to evaluate the safety and effects of intravenous injection of formalin on various haematology, serum biochemistry and coagulation parameters in normal adult Holstein cows.

\section{Materials and Methods}

This study was approved by the Jordan University of Science and Technology Animal Care and Use Committee. Six healthy adults (2-4 years of age) Holstein dairy cows with an average weight of $550 \mathrm{~kg}$ were used. Before enrollment in the study, cows were physically examined a complete blood count (CBC) and serum biochemical analyses were performed. Only healthy cows were used in the study.

Each cow received 2 intravenous injections of formalin at 2 different concentrations $(0.37 \%$ and $0.185 \%) 1$ week apart. To prepare the solutions, $5 \mathrm{ml}$ and $2.5 \mathrm{ml}$ of $37 \%$ formaldehyde solution (Chemanol, Saudi Arabia) were added to $495 \mathrm{ml}$ and $497.5 \mathrm{ml}$ normal saline respectively, using $0.2 \mu \mathrm{m}$ single use filter (Minisart, Sigma, Germany) to obtain $0.37 \%$ and $0.185 \%$ formalin solutions, respectively. The drug was then injected intravenously over 5 minutes using jugular intravenous catheter (Angiocath, 16GA X 5.25", Medline Industries, Illinois, USA).

The safety of the drug was evaluated by monitoring physical examination parameters such as rectal temperature, heart rate, respiratory rate, capillary refill time, rumen motility, and any changes in behaviour (salivation, urination and defecation, tremors etc.) during administration and for 24 hours after injection.

Whole blood samples were collected in plain, EDTA and citrate containing tubes before each injection (Time 0), and at 15, 30, 60, and 120 minutes and at 24 hours after administration for evaluation of haematology and serum biochemistry parameters. The following parameters were evaluated: total white blood cell count (WBC), red blood cell count (RBC), haemoglobin concentration $(\mathrm{Hb})$, packed cell volume $(\mathrm{PCV})$, mean corpuscular volume (MCV), mean corpuscular haemoglobin concentration (MCHC) and platelets count were determined using an electric cell counter (ABC Vet haematology analyzer, ABX Diagnostics, Maizy, France). Fibrinogen concentration was determined using heat-precipitation method (Thrall et al., 2004). Serum biochemical evaluation includes total protein, blood urea nitrogen, creatinine, aspartate aminotransferase (AST), alanine aminotransferase (ALT), alkaline phosphatase (ALP), calcium, sodium, chloride and potassium using previously published methods (Thrall et al., 2004).

Whole blood in citrate-containing tubes was used to determine the following clotting parameters: activated partial thromboplastin time (APTT) (STAC.K. Prest, Stago, France), prothrombin time (PT) (Néoplastine CI Plus, Stago France), thrombin time (TT) (STA-Thrombin, Stago, France), and D-Dimers (D-Di Test, Stago, France). Laboratory analyses were performed within 2-3 hours of sample collection according to manufacturer's recommendations.

Data was presented as mean \pm standard error (SE). Repeated measure analysis of each of the evaluated variables was performed using GLM repeated measures. Post-hoc pairwise comparisons were performed using the Bonferroni test. Differences were considered statistically significant if the $\mathrm{P} \leq 0.05$. The analysis was conducted using statistical software (SPSS, Version 19.0, SPSS Inc, Chicago, USA).

\section{Results}

All cows tolerated well the intravenous administration of $0.37 \%$ and $0.185 \%$ formalin solutions without showing overt toxic signs. In cows administered $0.37 \%$, however, mild signs of toxicity were observed and included serous ocular discharge and frequent defecation only during drug administration. There were no significant changes in any of the measured clinical variables including the rectal temperature, heart rate, respiratory rate, mucus membrane colour, capillary refill time, and rumen motility at any time point.

There were no significant differences in any of the measured parameters in the haematology and serum biochemistry profiles at any time point. All values were within normal range (Tables 1-4).

Tables 5 and 6 show results of the coagulation profiles in cows administered $0.37 \%$, and $0.185 \%$ formalin solution, respectively. The administration of $0.37 \%$ formalin resulted in a significant decrease in APTT clotting times at 30, 60, and 120 minutes after administration. Thrombin time was also significantly decreased in this group at 15, 30, 60, and 120 minutes after administration. Platelets count was significantly increased at 60 and 120 minutes in this group. No significant changes were observed in PTT, fibrinogen concentrations and D-dimers at any time point. 
Res. Opin. Anim. Vet. Sci., 2016, 6(7): 206-210.

Table 1: Means \pm SE for certain haematology parameters in healthy adult dairy cows before and after administration of $0.37 \%$ formalin intravenously

\begin{tabular}{ccccccl}
\hline \multirow{2}{*}{24 hours } & \multicolumn{5}{c}{ Time (minutes) } & \multirow{2}{*}{ Parameter } \\
\cline { 2 - 5 } & 120 & 60 & 30 & 15 & T0 & \\
\hline $10 \pm 1.8$ & $11 \pm 1.8$ & $11 \pm 1.8$ & $11 \pm 1.8$ & $10 \pm 1.8$ & $9.5 \pm 1.8$ & WBC $\left(\times 10^{9}\right.$ cells/L) \\
$6 \pm 0.5$ & $6 \pm 0.5$ & $6 \pm 0.5$ & $6 \pm 0.5$ & $6 \pm 0.5$ & $6 \pm 0.5$ & $\mathrm{RBC}\left(\mathrm{x} 10^{12}\right.$ cells/L) \\
$90 \pm 3.3$ & $130 \pm 3.32$ & $110 \pm 3.6$ & $100 \pm 3.3$ & $100 \pm 3.3$ & $100 \pm 3.3$ & $\mathrm{HB}(\mathrm{g} / \mathrm{L})$ \\
$28 \pm 1.6$ & $29 \pm 1.6$ & $29 \pm 1.7$ & $29 \pm 1.6$ & $29 \pm 1.6$ & $30 \pm 1.7$ & $\mathrm{PCV} \%$ \\
$44 \pm 1.0$ & $45 \pm 1.0$ & $45 \pm 1.0$ & $45 \pm 1.0$ & $45 \pm 1.0$ & $45 \pm 1.0$ & $\mathrm{MCV}(\mathrm{fl})$ \\
$15 \pm 5.5$ & $18 \pm 5.5$ & $15 \pm 6.0$ & $15 \pm 5.5$ & $15 \pm 5.5$ & $15 \pm 5.5$ & $\mathrm{MCH}(\mathrm{pg})$ \\
$340 \pm 120$ & $340 \pm 120$ & $340 \pm 130$ & $340 \pm 120$ & $330 \pm 120$ & $330 \pm 120$ & $\mathrm{MCHC}(\mathrm{g} / \mathrm{L})$ \\
\hline
\end{tabular}

$\overline{\mathrm{WBC} \text {, White blood cell count; RBC, Red blood cell count; Hb, Haemoglobin concentration; PCV, Packed cell volume; MCV }}$ Mean corpuscular volume; MCHC, Mean corpuscular haemoglobin concentration.

Table 2: Means \pm SE for certain haematology parameters in healthy adult dairy cows before and after administration of $0.185 \%$ formalin solution intravenously

\begin{tabular}{ccccccl}
\hline \multirow{2}{*}{24 hours } & \multicolumn{5}{c}{ Time (minutes) } & \multirow{2}{*}{ Parameter } \\
\cline { 2 - 5 } & 120 & 60 & 30 & 15 & T0 & \\
\hline $13 \pm 1.8$ & $10 \pm 1.8$ & $11 \pm 1.8$ & $12 \pm 1.8$ & $12 \pm 1.8$ & $13 \pm 1.8$ & WBC $\left(\times 10^{9}\right.$ cells/l) \\
$7 \pm 0.5$ & $7 \pm 0.5$ & $7 \pm 0.5$ & $7 \pm 0.5$ & $8 \pm 0.5$ & $8 \pm 0.5$ & $\mathrm{RBC}\left(\mathrm{x} 10^{12}\right.$ cells/l) \\
$100 \pm 3.3$ & $100 \pm 3.3$ & $100 \pm 3.3$ & $100 \pm 3.3$ & $120 \pm 3.3$ & $110 \pm 3.3$ & $\mathrm{HB}(\mathrm{g} / \mathrm{l})$ \\
$31 \pm 1.6$ & $31 \pm 1.6$ & $30 \pm 1.6$ & $31 \pm 1.6$ & $34 \pm 1.6$ & $34 \pm 1.6$ & $\mathrm{PCV} \%$ \\
$43 \pm 1.0$ & $44 \pm 1.0$ & $45 \pm 1.0$ & $44 \pm 1.0$ & $44 \pm 1.0$ & $44 \pm 1.0$ & $\mathrm{MCV}(\mathrm{fl})$ \\
$14 \pm 5.5$ & $15 \pm 5.5$ & $15 \pm 5.5$ & $15 \pm 5.5$ & $14 \pm 5.5$ & $15 \pm 5.5$ & $\mathrm{MCH}(\mathrm{pg})$ \\
$330 \pm 120$ & $330 \pm 120$ & $340 \pm 120$ & $330 \pm 120$ & $330 \pm 120$ & $330 \pm 120$ & $\mathrm{MCHC}(\mathrm{g} / \mathrm{l})$ \\
\hline
\end{tabular}

WBC, White blood cell count; RBC, Red blood cell count; Hb, Haemoglobin concentration; PCV, Packed cell volume; MCV, Mean corpuscular volume; MCHC, Mean corpuscular haemoglobin concentration

Table 3: Means \pm SE for certain blood biochemistry parameters in healthy adult dairy cows before and after administration of $0.37 \%$ formalin intravenously

\begin{tabular}{ccccccl}
\hline \multirow{2}{*}{24 hours } & \multicolumn{7}{c}{ Time (minutes) } & \multirow{2}{*}{ Parameter } \\
\cline { 2 - 5 } & 120 & 60 & 30 & 15 & T0 \\
\hline $41 \pm 4.0$ & $21 \pm 4.0$ & $23 \pm 4.0$ & $23 \pm 4.0$ & $26 \pm 4.0$ & $30 \pm 4.0$ & AST (IU/l) \\
$13 \pm 3.6$ & $15 \pm 3.6$ & $13 \pm 3.6$ & $18 \pm 3.6$ & $11 \pm 3.6$ & $13 \pm 3.6$ & ALT (IU/l) \\
$67 \pm 17$ & $86 \pm 17$ & $79 \pm 17$ & $89 \pm 17$ & $69 \pm 17$ & $79 \pm 17$ & AIP (IU/l) \\
$82 \pm 0.1$ & $80 \pm 0.1$ & $81 \pm 0.1$ & $79 \pm 0.1$ & $81 \pm 0.1$ & $82 \pm 0.1$ & Total protein (g/l) \\
$6.8 \pm 0.6$ & $6.8 \pm 0.6$ & $6.5 \pm 0.6$ & $7 \pm 0.6$ & $7 \pm 0.6$ & $6.5 \pm 0.6$ & BUN (mmol/l) \\
$60 \pm 8.8$ & $70 \pm 8.8$ & $88 \pm 8.8$ & $70 \pm 8.8$ & $88 \pm 8.8$ & $66 \pm 8.8$ & Creatinine $(\mu \mathrm{mol} / 1)$ \\
$2 \pm 0.05$ & $2 \pm 0.05$ & $2 \pm 0.05$ & $2 \pm 0.05$ & $2 \pm 0.05$ & $2 \pm 0.05$ & Calcium (mmol/l) \\
$137 \pm 1.6$ & $138 \pm 1.6$ & $140 \pm 1.6$ & $141 \pm 1.6$ & $143 \pm 1.6$ & $141 \pm 1.6$ & Sodium (mmol/l) \\
$101.9 \pm 3.9$ & $105 \pm 3.9$ & $102.1 \pm 3.9$ & $101.5 \pm 3.9$ & $101.1 \pm 3.9$ & $101.9 \pm 3.9$ & Chloride (mmol/l) \\
$4.5 \pm 1.4$ & $3.8 \pm 1.4$ & $4.0 \pm 1.4$ & $4.0 \pm 1.4$ & $5.0 \pm 1.4$ & $4.0 \pm 1.4$ & Potassium $(\mathrm{mmol} / \mathrm{l})$ \\
\hline
\end{tabular}

AST, Aspartate aminotransferase; ALT, Alanine aminotransferase; ALP, Alkaline phosphatase; BUN, Blood urea nitrogen

Table 4: Means \pm SE for certain blood biochemistry parameters in healthy adult dairy cows before and after administration of $0.185 \%$ formalin intravenously.

\begin{tabular}{|c|c|c|c|c|c|c|}
\hline \multirow{2}{*}{24 hours } & \multicolumn{5}{|c|}{ Time (minutes) } & \multirow{2}{*}{ Parameter } \\
\hline & 120 & 60 & 30 & 15 & T0 & \\
\hline $21 \pm 4.0$ & $25 \pm 4.0$ & $26 \pm 4.0$ & $26 \pm 4.0$ & $20 \pm 4.0$ & $22 \pm 4.0$ & AST (IU/l) \\
\hline $10 \pm 3.6$ & $20 \pm 3.6$ & $12 \pm 3.6$ & $16 \pm 3.6$ & $15 \pm 3.6$ & $15 \pm 3.6$ & $\operatorname{ALT}(\mathrm{IU} / \mathrm{l})$ \\
\hline $83 \pm 17$ & $72 \pm 17$ & $82 \pm 17$ & $85 \pm 17$ & $84 \pm 17$ & $90 \pm 17$ & AIP (IU/l) \\
\hline $82 \pm 0.1$ & $81 \pm 0.1$ & $81 \pm 0.1$ & $82 \pm 0.1$ & $80 \pm 0.1$ & $82 \pm 0.1$ & Total protein $(\mathrm{g} / \mathrm{l})$ \\
\hline $5.5 \pm 0.6$ & $5.7 \pm 0.6$ & $5.5 \pm 0.6$ & $5.3 \pm 0.6$ & $5.5 \pm 0.6$ & $5.3 \pm 0.6$ & BUN (mmol/l) \\
\hline $90 \pm 8.8$ & $90 \pm 8.8$ & $79 \pm 8.8$ & $66 \pm 8.8$ & $88 \pm 8.8$ & $88 \pm 8.8$ & Creatinine $(\mu \mathrm{mol} / \mathrm{l})$ \\
\hline $2.25 \pm 0.02$ & $2.25 \pm 0.02$ & $2 \pm 0.02$ & $2 \pm 0.02$ & $2 \pm 0.02$ & $2.25 \pm 0.05$ & Calcium (mmol/l) \\
\hline $137 \pm 1.6$ & $141 \pm 1.6$ & $142 \pm 1.6$ & $141 \pm 1.6$ & $140 \pm 1.6$ & $138 \pm 1.6$ & Sodium (mmol/l) \\
\hline $106 \pm 3.9$ & $103 \pm 3.9$ & $101 \pm 3.9$ & $103 \pm 3.9$ & $90 \pm 3.9$ & $104 \pm 3.9$ & Chloride (mmol/l) \\
\hline $4.0 \pm 1.4$ & $4.0 \pm 1.4$ & $4.0 \pm 1.4$ & $4.5 \pm 1.4$ & $5.0 \pm 1.4$ & $4.0 \pm 1.4$ & Potassium $(\mathrm{mmol} / \mathrm{l})$ \\
\hline
\end{tabular}

AST, Aspartate aminotransferase; ALT, Alanine aminotransferase; ALP, Alkaline phosphatase; BUN, Blood urea nitrogen 
Table 5: Means \pm SE coagulation parameters in healthy adult dairy cows before and after administration of $0.37 \%$ formalin intravenously

\begin{tabular}{ccccccl}
\hline \multirow{2}{*}{24 hours } & \multicolumn{5}{c}{ Time (minutes) } & \multirow{2}{*}{ Parameter } \\
\cline { 2 - 6 } & 120 & 60 & 30 & 15 & T0 \\
\hline $250 \pm 35$ & $350 \pm 35^{\text {à }}$ & $320 \pm 37^{\grave{a}}$ & $250 \pm 35$ & $290 \pm 35$ & $280 \pm 35^{\text {a }}$ & Platelet (x109 cells/l) \\
$23 \pm 9$ & $24 \pm 9$ & $24 \pm 9$ & $23 \pm 9$ & $24 \pm 9$ & $28 \pm 9$ & PT (seconds) \\
$47 \pm 4$ & $42 \pm 4^{\grave{a}}$ & $43 \pm 4^{\grave{a}}$ & $43 \pm 4^{\text {à }}$ & $48 \pm 4$ & $53 \pm 4^{\text {a }}$ & APTT (seconds) \\
$36 \pm 1.9$ & $30 \pm 1.9^{\text {à }}$ & $34 \pm 1.9^{\text {à }}$ & $32 \pm 1.9^{\text {à }}$ & $30 \pm 1.9^{\text {à }}$ & $38 \pm 1.9^{\text {a }}$ & TT (seconds) \\
$<0.5$ & $<0.5$ & $<0.5$ & $<0.5$ & $<0.5$ & $<0.5$ & D-dimer (ng/ml) \\
$14.5 \pm 0.8$ & $14.5 \pm 0.9$ & $13.8 \pm 0.8$ & $14.7 \pm 0.9$ & $13.8 \pm 0.8$ & $14 \pm 0.8$ & Fibrinogen $(\mu \mathrm{mol} / \mathrm{l})$ \\
\hline
\end{tabular}

PT, Prothrombin time; APTT, Activated partial thromboplastin time; TT, Thrombine time; ${ }^{a}$ in the same raw indicate significant difference at $\mathrm{P} \leq 0.05$

Table 6: Means \pm SE of coagulation parameters in healthy adult dairy cows before and after administration of $0.185 \%$ formalin intravenously

\begin{tabular}{|c|c|c|c|c|c|c|}
\hline \multirow{2}{*}{24 hours } & \multicolumn{5}{|c|}{ Time (minutes) } & \multirow{2}{*}{ Parameter } \\
\hline & 120 & 60 & 30 & 15 & T0 & \\
\hline $275 \pm 35$ & $320 \pm 35$ & $320 \pm 35$ & $375 \pm 35$ & $350 \pm 35$ & $360 \pm 35$ & Platelet $\left(\mathrm{x} 10^{9}\right.$ cells/1) \\
\hline $25 \pm 9$ & $24 \pm 9$ & $25 \pm 9$ & $24 \pm 9$ & $24 \pm 9$ & $26 \pm 9$ & PT (seconds) \\
\hline $58 \pm 4.0^{\text {à }}$ & $50 \pm 4.0^{\text {à }}$ & $62 \pm 4.0$ & $62 \pm 4.0$ & $64 \pm 4.0$ & $67 \pm 4.0^{\mathrm{a}}$ & APTT (seconds) \\
\hline $34 \pm 1.9$ & $33 \pm 1.9$ & $30 \pm 1.9^{a ̀}$ & $30 \pm 1.9^{\text {à }}$ & $30 \pm 1.9^{\text {à }}$ & $36 \pm 1.9^{\mathrm{a}}$ & TT (seconds) \\
\hline$<0.5$ & $<0.5$ & $<0.5$ & $<0.5$ & $<0.5$ & $<0.5$ & D-dimer $(\mathrm{ng} / \mathrm{ml})$ \\
\hline $15 \pm 0.9$ & $15 \pm 0.9$ & $16 \pm 0.9$ & $16.5 \pm 0.9$ & $16 \pm 0.9$ & $14.5 \pm 0.9$ & Fibrinogen $(\mu \mathrm{mol} / \mathrm{l})$ \\
\hline
\end{tabular}

PT, Prothrombin time; APTT, Activated partial thromboplastin time; TT, Thrombine time; ${ }^{\text {an }}$ the same raw indicate significant difference at $\mathrm{P} \leq 0.05$

In cows administered $0.185 \%$ formalin, there was a significant decrease of APTT clotting times at 120 minute that remained at significantly lower levels at 24 hour after administration. Thrombin time was also significantly lower at 15, 30, and 60 minutes after administration. There were no significant differences in PTT, platelet counts, fibrinogen concentrations and Ddimers in this group at any time point.

\section{Discussion}

Since a safe and effective dose of formalin for intravenous administration in cattle has not been established and systemic toxic effects due to formalin injection are expected, 2 low doses of formalin $(0.37 \%$ and $0.185 \%$ ) were evaluated in this study. This study showed that cows tolerated very well the administration of both $0.37 \%$ and $0.185 \%$ solutions of formalin intravenously with no overt clinical toxic signs.

Although cows that received the higher concentration $(0.37 \%)$ a mild and clinically not significant signs of distress were reported such as serous ocular discharge and frequent defecation. These signs could be considered in all cattle subjected to mild stress, such as restraining and handling.

All vital signs, including the heart rate, respiration rate, rectal temperature and rumen motility patterns were within normal limits in all cows which confirms that cows did not suffer noticeable systemic toxicity such as hepersensitivity reactions. These results were in agreement with the results obtained in normal horses after the administration of $0.37 \%$ formalin solution intravenously (Taylor et al., 2000). Similar to our trial, Tylor et al. (2000) used 2 different doses of formalin in his study. He used a $0.37 \%$ and $0.74 \%$ solutions. He reported toxic signs such as muscle fasciculations, tachycardia, tachypnea, serous ocular and nasal discharge, agitation, and restlessness in horses received the higher dose of formalin $(0.74 \%)$.

Formalin is a known toxic and carcinogenic substance. After systemic administration or absorption, formalin is converted to formic acid and formate (Kiernan 2000; EFSA 2014). Formic acid inhibits cholinesterase, succinate oxidation, anaerobic glycolysis and hexokinase (Kiernan, 2000; EFSA 2014). In human beings, formalin toxicity is due to high levels of formic acid. It has been reported that the toxic levels of formic acid are $0.8 \mathrm{~g} / \mathrm{l}$ in blood and $0.66 \mathrm{~g} / \mathrm{l}$ in urine (EFSA2014). Formaldehyde is also a hepatotoxic drug (EFSA 2014). In this study, the haematology and serum biochemical analyses showed no significant changes in any of the studied parameters indicating no systemic toxic signs associated with the administration of both dose levels of formalin in adult dairy cows. These results are in agreement with those reported by Tylor et al. (2000) in horses.

The administration of $0.37 \%$ formalin solution intravenously in adult dairy cows resulted in a significant enhancement of coagulation as indicated by a significant reduction in the clotting times involving the APTT and TT. Platelet numbers were also significantly increased. The administration of $0.37 \%$ solution of formalin appeared to more significantly enhance clotting times than the administration of the 
lower dose $(0.185 \%)$. These results are in contrary to those obtained by Tylor et al. (2000) in horses who found no significant changes in any of the clotting parameters after either dose of formalin administered $(0.37 \%$ and $0.74 \%)$. Tylor et al. (2000) explained his findings by suggesting that formalin works by enhancing the coagulation mechanisms in horses were the clotting cascade is already activated by the damaged endothelium (Tylor et al., 2000).

The mechanism of action of formalin as a procoagulant has not been fully demonstrated. Locally in cases of urinary bladder bleeding, formalin works to stop haemorrhage by rapidly fixing the bladder mucosa through the formation of protein cross-linking (Manikandan et al., 2010). Systemically, alteration in coagulation parameters following formalin administration is suggested by the alterations in platelet or endothelial cell surface proteins, resulting in activation of platelets or decreased endothelial permeability resulting in the initiation of the clotting mechanisms (Kiernan, 2000). It is also plausible to think that one of formaldehyde metabolites such as formic acid or formate or may be some other yet unknown molecule could have the desirable effect on the coagulation cascade.

results of this study showed that the intravenous administration of $0.37 \%$ formalin solution is safe with a pro coagulation effects in normal adult dairy cows. However, further research is still warranted to evaluate its effects in cattle with active hemorrhage. It is also necessary to determine milk and meat withholding periods after intravenous administration before the use of formalin in lactating dairy cattle could be safely recommended.

\section{Acknowledgements}

The authors would like to thank the Deanship of Research at Jordan University of Science and Technology for sponsoring this project (project number: 46/2015). We also would like to thank the staff of the University Agricultural Research Farm for their valuable assistance.

\section{References}

Choong SKS, Walkden M, Kirby R (2000) The management of intractable haematuria. J Br Assoc Uroll Surg 86: 951-959.

Divers TJ, Peek SF (2008) Rebhun's Diseases of Dairy Cattle. 2nd ed. St. Louis, Saunders.

Dougherty S, Palmer J (2008) Use of intralesional formalin administration for treatment of a subepiglottic cyst in a horse. J Amer Vet Med Assoc 233: 463-465.

Doyle AJ, Freeman DE, Rapp H, Murrell JA, Wilkins PA (2003) Life-threatening hemorrhage from enterotomies and anastomoses in 7 horses. Vet Surg 32: 553-558.

EFSA (2014) Panel on Additives and Products or Substances used in Animal Feed. Eur Food Saf Auth J, 12:, 3561.

Frazer GS (2003) Current therapy in equine medicine, 5 th ed. St. Louis, Saunders.

Henrikson TD, Moore L, Biller DS, Schermerhorn T (2004) Intravesical instillation of dilute formalin for the treatment of severe hemorrhagic emphysematous cystitis in a diabetic dog. J Amer Anim Hosp Assoc 40: 64-68.

Jones W (1998) IV formalin to control hemorrhage. J Equine Vet Sci 18: 581.

Kang JC, Chao P, Wu C, Lee C, Yeh C, Hsiao C, Jao S (2003) Endoscopic therapy with topic formalin for treatment of refractory lower gastrointestinal bleeding. J Med Sci 23: 161-164.

Kiernan JA (2000) Formaldehyde, formalin, paraformaldehyde and glutaraldehyde: What they are and what they do. Microbiol Today 1: 8-12.

Lee S, Park Y, Sohn SK (2007) Formalin application for the treatment of radiation-induced hemorrhagic proctitis. Yonsei Med J 48: 97-100.

Manikandan R, Kumar S, Dorairajan LN (2010) Hemorrhagic cystitis: A challenge to the urologist. Indian J Urol 26: 159-166.

Mohamed A, Mohammed R, Hicham E (2012) The Use of intravesical formalin for hemorrhagic cystitis: our experience. Urolology 3: 3412.

Neto T, Mariano R,Teixeira F, Menezes A, Mariano A (2011) Evaluation of the effectiveness of $4 \%$ formalin in the treatment of hemorrhagic actinicproctitis. J Coloproctol 31: 262-267.

Radostits OM, Gay CC, Hinchcliff KW, Constable PD (2007) Veterinary Medicine, A Textbook of the Diseases of Cattle, Horses, Sheep, Pigs, and Goats. $10^{\text {th }}$ ed., Phyladelphia, Saunders.

Santschi EM (1999) Large Animal Urogenital Surgery. Baltimore, Williams \& Wilkins.

Taylor EL, Sellon DC, Wardrop KJ, Hines MT, Kingston JK (2000) Effects of intravenous administration of formaldehyde on platelet and coagulation variables in healthy horses. Amer J Vet Res 61: 1191-1196.

Thrall MA, Baker DC, Campbell TW, Denicola DB, Fettman MJ, Lassen DE, Rebar A, Weiser G (2004) Veterinary Hematology and Clinical Chemistry. Philadelphia, Williams \& Wilkins. 